\title{
Using Action Research as the Basis for Transforming a Workplace Culture so that Integration of Overseas Registered Nurses to the Nursing Home Clinical Setting be more Adaptive, Inclusive and Mutually Supportive.
}

\section{Cynthia Baluyot}

Department of Nursing and Health Promotion, Oslo Metropolitan University, Pilestredet 32, 0130 Oslo, Norway

\author{
Article Details \\ Article Type: Research Article \\ Received date: $15^{\text {th }}$ December, 2018 \\ Accepted date: $02^{\text {nd }}$ March, 2019 \\ Published date: $05^{\text {th }}$ March, 2019
}

"Corresponding Author: Cynthia Baluyot, Department of Nursing and Health Promotion, Oslo Metropolitan University, Pilestredet 32, 0130 Oslo, Norway. E-mail: cyntba@oslomet.no

Citation: Baluyot C (2019) Using Action Research as the Basis for Transforming a Workplace Culture so that Integration of Overseas Registered Nurses to the Nursing Home Clinical Setting be more Adaptive, Inclusive and Mutually Supportive. Sub-title: How to integrate overseas registered nurses into the clinical setting of a nursing home in Norway?. J Comp Nurs Res Care 4: 137. https://doi.org/10.33790/jenrc1100137.

Copyright: $(02019$, This is an open-access article distributed under the terms of the Creative Commons Attribution License 4.0, which permits unrestricted use, distribution, and reproduction in any medium, provided the original author and source are credited.

\begin{abstract}
Research question: How to integrate overseas registered nurses into the clinical setting of a nursing home in Norway?

Research problem: Newly arrived overseas registered nurses experience difficulties adjusting to the clinical setting in one of the institutions for old people in Norway.

Purpose: The purpose of the study shall be to develop a basic knowledge that will stimulate and improve competence in multicultural nursing in the clinical area. It will help develop research studies in nursing education and practice in relation to working conditions in a multi-cultural teamwork.

Theory: Multicultural nursing is a part of nursing that appreciates and accepts person/s' culture, not in the sense of approving all aspects of those cultures, but learning and understanding how a given culture canexpress care values, illness, healthand behavior of its own members [1].
\end{abstract}

Method: Qualitative research with a hermeneutical perspective is used. Action research [2] is the chosen method for this research due to its collaborative, reflective and evolutionary process of bringing about change. To ensure the effectiveness and trustworthiness of the study, focus group discussions and critical reflections are used. The data analysis is done through the hermeneutical approach according to level of interpretation.

Ethical considerations: Respondents received information about the research and other related matters in which the respondents are to participate. Ethical principles about confidentiality, anonymity and voluntary consent strictly observed. Permission granted from the head of the county where the nursing home is located.

Results: Results reveal that diversity issues such as in communication, different educational background, attitudes, values and cultural expectations, power dynamics and social avoidance and rejection are the underlying challenges of overseas registered nurses in adjusting to the Norwegian clinical setting.

Implications: Findings imply that the institution needs to provide a working climate that will promote professional and social integration to both the Norwegian registered nurses and overseas registered nurses.

Keywords: integration, overseas registered nurses, nursing home, clinical setting and culture, action research

\section{Introduction}

The increasing workforce demands in the Norwegian clinical setting urged employers to hire overseas registered nurses (ORNs). In 2003 for example, there were 1740 ORNs given Norwegian nurse registration [3]. These nurses represented many countries around the world including Asia, East and Central Europe, Africa and other Western countries. As of today, the number of overseas registered nurses into Norwegian nurse registration hasdecreased because the Norwegian Directorate for Health \& Social Affairs (2018) continuously regulates their requirements to qualify ORNs to the Norwegian nursing professional system. Countries like Asia for example;the nursing curricula deviate from Norwegian Nursing curriculum more or less in theories \& practice. Moreover, along the process of meeting the host country`s regulations, newly arrived ORNs find it difficult to adjust to the Norwegian clinical setting [1,45]. There is a need to assist ORNs in adjusting to the host country's clinical work setting, health system and professional and social integration.

\section{Multicultural Nursing}

Transcultural nursing [6], is the first culture care theory in nursing. The theory "focuses on comparative study and analysis of different cultures and subcultures in the world with respect to their caring behavior, nursing care and illness, values in health, beliefs, and patterns of behavior with the goal of developing a scientific and humanistic body of knowledge in order to provide culture-specific and culture-universal nursing care practice".

The definition above means that nursing integrates culture into nursing education and practice in order to understand diversity and universality of care. Culture and care are bound together to conceptualize culture care as relevant to nursing. Others call it cross-cultural 
nursing and intercultural nursing (Hanssen 2002). Terms transcultural nursing and cross-cultural nursing are comparative in nature, while intercultural nursing focuses on meeting cultureswith equal responsibility and account ability between persons, as they are different and dissimilar in world views and situations [7]. The author of this article agrees with the later and claims that multicultural nursing appreciates and accepts others 'cultures, not in the sense of approving all aspects of those cultures, but learning and understanding how a given culture can express care values, illness, healthand behavior of its own members [1]. This is an essential aspectto consider in nursing education and practice.

\section{Literature review}

Existing research on how ORNs adjust to their host countries are few. However, studies $[8,4]$, reveal that ORNs though more or less equally employed as the host countries` nurses, still they experience difficulties at work on language literacy, carrier building and professional socialization. According to $[8,4,9]$, all concerned into working conditions in the clinical setting, claim that these nurses at times experience feelings of marginalization, exclusion and discrimination. The same studies reveal that there is limited openness about these difficulties, and this reticence adds to the situation. The diversity problems [9], for e.g. in America on the early 90`s, about communication, educational background, attitudes, values and cultural expectations, power dynamics and social rejection, are probably the same factors that contribute to the underlying tensions in terms of ORNs adjusting to the clinical setting [1]. Countries like Australia, England, America, Canada, New Zealand and Norway arecountries having similarities on diversity issues $[1,10,8]$. Furthermore, a study [9], into working conditions in clinical setting, claims that nursing work force needs to provide support to enable ORNs to adapt to working in a different care system.

\section{Research Methodology \& design}

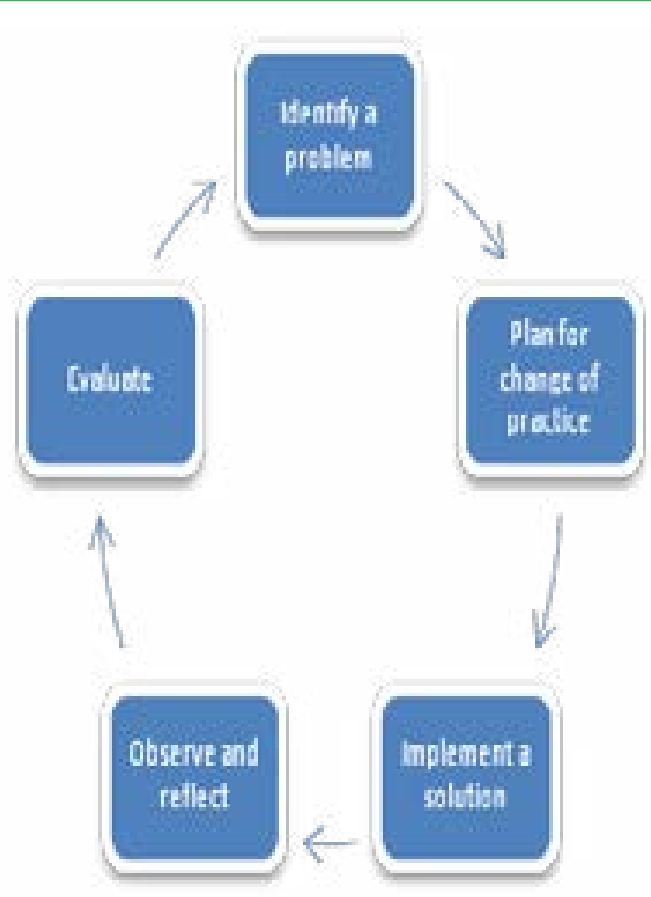

Fig.1. Action Research Process [2]. Action research is a form of collective inquiry undertaken by participants in organizations, social \& practice situations with the aim of making a change [2]. According to the same authors [2], action research emphasizes collaboration, critical reflective processes \& evaluation to make changes and generate knowledge. Actually, it was on his paper about minority problems [2], who claim first that,
"In action research, human beings and practice settings are linked to language and discourses, activities, practices and social relationships and forms of organization. It improves the productivity, rationality and justice of their own social or educational practices, as well as their understanding of these practices and situations in which practices are carried out"

Relating to the above definition, in this research,the first two pairs of terms refers to the language problems and discourses between Norwegian registered nurses (NRNs) and ORNs. The last two pairs apply for the distinction between the ORNs and the system. To address the relationships between and within the pairs of terms, ORNs \&NRNs would identify and define their concerns, reflect and critically examine to make changes in practice. In other words, action research as grounded by critical theory, attempts to change practice by involving researcher and participants, discourses, social relationships and forms of organization in order to make a change.

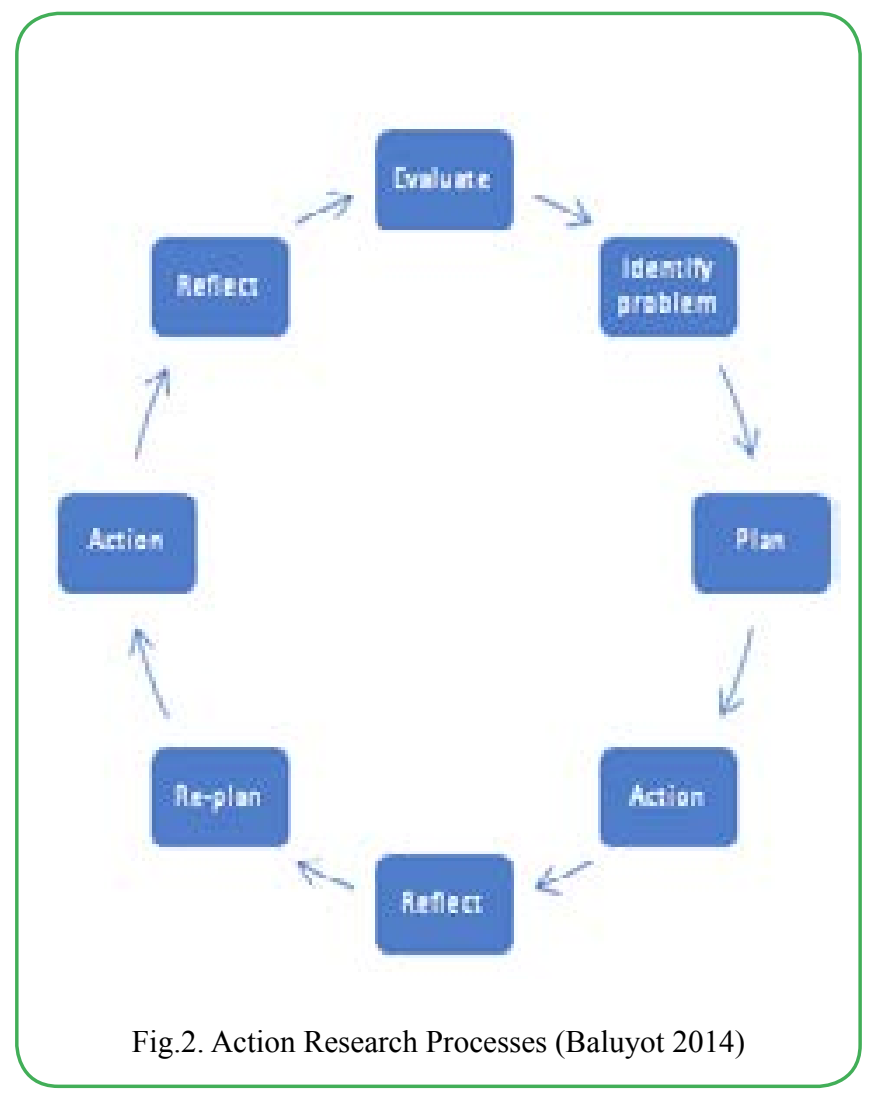

As illustratedin Fig.1, action research shows a systematic reflective cyclical process consisting of planning, acting, observing, reflecting and evaluating action [2]. Action research process in Fig.2 shows that the cycle continues asnew areas of investigation emerged, new actions planned and implemented, reflected and evaluated [1].The cyclic process provided participants time and effort to know each other; express and understand their concerns at work and social relationships, reflect and react for a better situation, learn and grow together in profession and social levels [1].

In this research project, action research provided a direction to facilitate the establishment of common values to make changes in practice. Supported the researcher in this account, claiming that action research provides the "mechanism for agreeing basic values as a precursor to change". The change primarily was little but gave the potential to generate similar changes throughout the whole institution.

\section{Purpose of the research project}

The purpose of the study should be to develop a basic knowledge 
that would stimulate and improve competence in multicultural nursing in clinical practice. It would also help develop research studies in nursing education and practice in relation to working conditions in a multicultural context. In other words, the study aims to bring about culture change in the clinical setting of a nursing home in Norway. The above purpose will strengthen the learning experience in promoting integration, as the NRNs nurses and ORNs learn to see, accept diversities and create a common culture \& professional values in practice.

\section{Setting and participants}

The home for the aged has 187 bed capacities with different services like short- and long-term rehabilitation units, psychiatry/ dementia care units, somatic units as well as somatic and dementia day-care centers. The employees, out of 44 nurse positions; half of it has different cultural background. We used one of the clinical wards for the focus group research project having the most ORNs in the entire institution. To collect data,we conducted eight focus group interview meetings to eight participants in an hour duration every time we did it. In addition, we created a focus interview group for leaders comprising the institution's nurse supervisor, nurse educator and six head nurses who acted as supervisors to the focus group before suggested solutions were implemented into actions.

\section{The research cyclical processes}

The focus group interview started with the identification of the problem. Diversity issues such as language barrier, different educational background, various attitudes, values and cultural expectations, power dynamics and socialization revealed. After analysis of the results from the first focus group interview, the researcher reported the diversity issues to the focus interview group and leaders` focus interview group. They discussed and reflected on presented results and later analyzed the need for change of the culture in the clinical setting. The leader of the institution suggested to the focus group that head nurses are to lead the development of a working environment to promote professional and social integration of the NRNs and ORNs. However, to start a new action plan, the leader suggested that it would be better to send head nurses to leadership education and training since they would need it in making a change.With a new working plan, a newcycle of discussions and reflections from the focus group emerged. A slight commotion arose from some participants because of the delay of the original plan. It is the researcher's duty to discuss and make the participants understand that a plan process be followed to succeed in the research project. The systematic integration planfor the ORN into the clinical setting remained untouched as the head nurses' education and training began, as they would play an important role in executing change into the clinical setting.

The change of plan required openness to all research participants. To bring about behavioral change between ORNs and NRNs, all participants must be aware of the need for change, understand, and learn together in order to strengthen the development of change. The focus group participants understood the situation, felt recognized, and were motivated to continue and sustain the process of change. To change practice, continues evaluation of the focus group plan provided us with a direction to facilitate the establishment of their common values. As a researcher, creating discourses in between cycle processes and facilitate different group level of discussions in the organization is necessary, for e.g. in the initial focus group and leader group meetings. After holding two focus groups discussion and reflection meetings, all agreed to implement actions on different levels in the institution. By doing that, personnel interests and engagement upheld.

The institution applied and got a financial support from their local municipal district and started to implement actions. In fall 2003, head nurses attended leadership part-time education and training for 2 semesters ( $30 \mathrm{CTS}$ ), a part of the community health care services leader`s development program (2003-2006), in the county of Oslo. In addition, a multicultural nursing seminar for the employees and a traditional social summer gathering with all employees, patients and relatives took place in the institution. Educational seminars in which personnel could apply are often available for personnel to promote individual development. Social gatherings, enriched by multicultural costumes, music \& dance happen almost every year.

When it comes to the ORNs, the institution collaborated with the Norwegian Nurses Organization arranged ORNs` work schedule and allow them attend the Norwegian language courses. Moreover, ORNs got permission to take the Norwegian National Nursing Course for the Norwegian nurse registration. Those ORNs who needed additional practice in psychiatry and geriatrics, took clinical training within the institution. Furthermore, we implemented mentorship program at work. The NRNs acted as role models and mentors to assist ORNs at daily work activities in the clinical setting. An ORN should have a permanent NRN mentor for at least 3-6 months period. The goal was to train ORNs into the Norwegian clinical practice setting and at the same time learn the Norwegian language and culture in everyday activities via colleagues. Daily nurse activities such as bedside care, sore treatment, medications, assist doctor's visits, documentation and leadership were some of the foci of mentorship program.

The mentorship program and self-directed personal development plan for ORNs and NRN scarried out into the system and taken later in the existing induction and evaluation program of the institution. Under probation period, individual evaluation is required every other 2 months for a period of one year to record progression on self-directed personal development plan. In that way, both the employer and newly arrived ORNs and NRNs became aware of their professional functions and responsibilities and for each other.

The NRNs and newly arrived ORNs have many challenges that require time and resources before they could create a climate that would promote professional and social integration in their clinical setting. For an ORN for instance, it would take several years before he/she becomes a competent nurse practitioner. [11] in [12], points out that it takes 2-3 years before one becomes a competent practitioner. This is proven by studies $[1,13]$, revealing that it takes 3-5 years before an overseas registered nurse can optimally function in practice. On the part of NRNs, they need also to adjust and accept diversity. Integration entails not only for the ORNs but among NRNs too.

The research period lasted for a year. The institution implemented several adjustments and changes on their place of work with positive results. The goal of building a professional and social climate would take time. The project had at least begun a process that would promote professional and social integration, not only for the ORNs but also for the Norwegian employees in the institution.

\section{Research analysis}

The research analysis used a hermeneutical approach through level of interpretation emphasizes, "Hermeneutics is thus the route to philosophical reflection, premised on the assumption that by following the indication of symbolic meanings one will arrive at a deeper understanding of human experience". Initially approaches such issues from a phenomenological perspective attempting to describe how phenomena appear and relate modes of appearance to subjective processes of consciousness. Critical refection consists a) naive reading, the text read by the researcher without having any knowledge of gathered data. b) read and understand by intuition, sensing and feeling what is thing called reality. c) rational reflection, systematically doing research governed by ideas, knowledge from earlier research and reflecting through experiences. Only then is the will of consciousness fully applied. The analysis in this study was structured based on Kvale`s hermeneutical approach and his 
reflective methods. The research data analysis has been a part of the cyclical process, in which collected data critically discussed, decided for an action,implemented, reflected and evaluated to see if clinical practice has improvedor the implemented actions re-evaluate until the organization reached the goalfor change and decided to put changed actions into system. The process took time and results were ample. However, ithas the potential to make changes and generate knowledge to the institution and organization.

\section{Results and Discussions}

\section{Communication Issue}

Language seems to be one of the significant problems in the research project. For ORNs, language learning is problematic not only because there is a mandatory Norwegian language testing but also it takes a while to learn and understand a new language. Once ORNs complete the language proficiency testing and nursing supplemental courses, they are able to start working as registered nurses. However, the study shows that language difficulties continue, because different nationalities have different meanings to verbal and non verbal behaviors, and usually not aware of the differences resulting to miscommunication. For e.g. one of the participants in the research shared that non-verbal communication is usual to Asian ORNs, who nod when ask about a nursing procedure, but does not necessarily mean understanding the message conveyed, just nodin respect to the conversant. This means a serious problem when one thinks of a nursing procedure to a patient care and the ORN could not do it in a proper manner due to misunderstanding. Research claim that cultural factors influence verbal and non verbal behaviors in multicultural interactions and communication processes [14]. Often times, these nuances led to miscommunication and unfavorable perception of ORNs resulting to provide less effective and safe patient care [15]. Furthermore, research [16] claims that differing interpretations of what is a demand rather than a request, and differing concepts of persuasion, suggestion and demonstration influenced employees' acceptance of task assignments. According to another study, it is difficult to understand sociocultural aspects of communication as in jokes, sarcasm, euphemisms and non verbal behaviors. Konmo suggests [17] in [18], to resolve this issue on communication, language and competence training should be of high priority because communicative competence directly affects patient safety and quality of care. However, adjustment to speaking the language and professional socialization really take time. Therefore, to communicate effectively with people of other cultures, it is important to be aware of one's style of communication and receptive of the diversity of others.

\section{Educational background}

This research project reveals that registered overseas nurses' cultural background affects the understanding of and practice of nursing. As shown in our research results, some ORNs have lower level of nursing education in their curriculum, which they in turn have to study two years more in the Norwegian college or university to be qualified as a nurse in Norway. Some lack number of hours to complete nursing subjects and clinical training, some do not have geriatric or psychiatry subject in their nursing study. According to studies, values and norms imposed during up bringing and education create conditions for functional preparedness in practice in the nursing profession $[1,5]$. Further more, nursing education is not the same around the world, and expectations for practice are different $[1,18,8]$. Most faculties had little or no preparation in culture in their academic programs $[1,18]$. Moreover, research shows that nurses in their field of study and practice need knowledge about multi-cultural competence; an area in nursing that has given little attention in many countries including Norway $[1,19]$. To attain cultural competence, educational institution, teachers in nursing and registered nurses in practice must have a cultural desire before they can actually be aware of cultures, gain cultural knowledge and skills and culturally communicate $[7,19]$. ORNs need a period of retraining to socialize into the host countries' way of nursing practice $[1,10]$.

\section{Attitudes, values and cultural expectations}

Aside from educational reason, ORNs and NRNs commitment to their own cultural beliefs, values and practices andsome racial attitudes and discriminatory practices which were hesitantly expressed in this research, might have brought workers into conflict. According to studies, $[1,16]$, conflicting interaction behaviors indicate measures of alienation, denial, tension, disputes, distrust, annoyances, anger, verbal attacks, confrontation etc. Moreover, the same studies claim that conflict in work place often occurs when the dominant culture expects others to fit in and behave accordingly to their rules and values $[1,16]$. Furthermore, conflict resolution styles and strategies also have a cultural base; some cultural styles emphasize confrontation, while others are comfortable with avoidance [1,9]. Research reveals that sensitivity to other individuals' belief system can promote individual perception and understanding [1,19,7]. In addition,when workers are able to reflect and see diversity in employees and able to use differences, they would be able to understand and meet the needs of the organization and the society that they are serving for $[1,16]$.

\section{Power dynamics}

Power dynamics also expressed reluctantly in this study because it is difficult to admit for ORNs and NRNs that power, prestige and privilege are becoming factors in hostilities in the development of conflict and discrimination in a multicultural setting. In this research, for e.g., ORNs felt imperior of the Norwegian assistant nurses who oftentimes felt practically superior to the newly arrived ORNs because most ORNs start as assistant nurses, not in a staff nurse position as ORNs still lack Norwegian nurse registration and adequate Norwegian language.This is a matter of power among assistant nurses\& ORNs feeling underdog due to less education in language \& nursing. According to a study [14], it is problematic to conceptualize "difference" as individual attributes because it is a complex concept with social and political implications, for example ORNs in Norway and elsewhere in the world. As there are, two levels of the meaning of difference depicted in the abovestudy, as "you are you" and difference as "incompetence". Negative meanings ascribed to difference in turn legitimize inequality and hold the potential to perpetuate racism [14]. To solve issues of power, suggested solutions like sensitivity to status differences and establishment of informal and normal norms in which employees can evaluate their behavior, understand each other and create organizational climate to promote integration in workplace $[1,9]$. ORNs may have differing experiences of teamwork. Therefore, discussing multidisciplinary and multi-professional team working can be helpful. Furthermore, clinical governance and standards of practice, contract terms and conditions, educational advancement, debates and reflections in clinical supervision are important to consider $[1,10]$.

\section{Organizational issues and social rejection}

ORNs, particularly those from Asia and Eastern Europe, hesitantly reported discomforting level of nurse peer rejection in this study. E.g. in this research is when an ORN applies for promotion at work, it is obvious that her/his foreign name determines not being called for work interview. Another alarming result, is for e.g., an ORN receives unpleasant comments and she/he does not reply to avoid conflict or really does not react because she/he does not understand the message. It seems that no NRNs take and report the issue or tell others stop treating ORNs with discomforting attitudes; rather some NRNs added sarcastic and uncomfortable comments and assume such attitudes as a joke. According to cited in [9], "there is a pattern of avoidance and discomfort when this issue regarding diversity arise". Such discomforting issues on ORNs` adjustment to work as in clinical setting received little attention and insufficient policy remedies 
to date, as [8] claimed, despite the potentially profound impact ORNs on workforce cohesion and supply, social rejection happens. Some claim that the lack of preparation from the host country and ORNs, are among factors that affect ORNs adapting to social environment and nonetheless the country's health system $[1,20]$. Moreover, insufficient psychosocial support, lack of systematic counseling and incompetence in transcultural nursing are among the factors that affect ORNs' integration to the system $[1,10]$.

\section{Research Implications}

ORNs need a period of retraining to socialize into the host countries' way of nursing practice. Training in nursing and language efficiency are important. However, training alone is not sufficient for today's world and the future. To employ ORNs, a culturally conducive environment in addition to induction and training programs are important $[1,10]$. We need a new mindset to develop professional and organizational changes, take advantage of each other's values and opportunities diversity brings to find and develop new ways of thinking. This study recommends that organizations adjust and/or change collectively onchallenging situations in clinical practice to provide anorganizational culture that encourages professional and social integration.

\section{Research methods`implications}

This research project has given the author the experience of knowing how action research differs from other traditional research methods. Action research has a cyclical process enabling participants to assess, reflect and work collectively in a decided solution in order to change and improve their practice [1,2]. However, it is argued that this cyclical process is what makes the method problematic, because one does not know when the collection and analysis of data end [21]. Action researchas experienced in this study connects reality faster than usual research methods. The gathered data decide an action in an effort to improve and systematize practice, instead of returning to the general theory.

Action research advantage is on its dialectic character [1]. Collection of data is through dialogue, collaboration and critical reflection [2]. The research is about, done with and for the participants. The research method requires the researcher to be more critical and observant on how and when to integrate theory and practice in between action and reflection, because the emphasis in action research design is on the methodology of critical praxis, [22], and collective integration of theory and practice [1].

Kvale claims in hermeneutics that valid knowledge arises when conflicting ideas are discussed in participants' communication processes. He claims further that validity is not just what method is used, but also on the researcher's ethical knowledge in evaluating the data results that are produced or generated. It is important to take the participants seriously, be humble of the participants` imparted meanings and situations for e.g. the results from the study, information; reports and reflections are back to the organization.According to [23], researcher must be aware of what she/he experiences, because personal knowledge entails emotional engagement, not only logic and rational analysis [12]. The validity and reliability depends on researcher's moral integrity in evaluating as well asrevealing data results and how knowledge is generated. This is probably one of the latest knowledge to share in public.

In this study, action research provided a direction to make thechanges and facilitate the establishment of common values in the Norwegian workplace culture that promotes mutual and better integration of overseas registered nurses and Norwegian registered nurses in their clinical setting. In integration, both parties, ORNs and NRNs have to change to create a common culture. The change primarily is small, but it has the potential to generate similar changes throughout the whole institution and may give knowledge to a broader public.

\section{Conclusion}

Cultural diversity continues to grow in healthcare workplace and so do cultural challenges like issues on communication, differing educational system, power dynamics, social rejection, insensitivity and unawareness of each other's motivation. These challenges occur in many places around the world including Norway. Industrialized countries recruiting from the global nursing market,to enable integration, they need to invest in providing mutual support, inclusion and adaptation of both overseas registered nurses and host countries' registered nurses to work within care system, social and cultural context.

\section{References}

1. Baluyot MAC (2014) In Tewes, R. \& Stockinger, A. (2014). Personal-entwiklung in Pflege-und Gesundheits-einrichtungen, Springer 2014.ISBN 978-3-642-37324-4.s.151-164.

2. Kemmis S, McTaggart R (2000) Participatory action research. In N.K. Denzin \& Y.S. Lincoln (eds.), Handbook of qualitative research. California: Sage.

3. Norwegian Registration Authority for Health Personnel (2003). Statistics for Foreign registered nurses nNorway.

4. Danielsen T (2000) Sykepleiere og Handlinger I et Flerkultur ellArbeidsmiljø,NSF,HiOSEFIA agkompetanse og kompetanse I fremmed kultur.Oslo,University of Oslo, Institute of Nursing Science, Osloforlaget.

5. Johannesen B (1993) Sykehjem med utenlandske sykepleiere. Tidskriftet I Sykepleien, nr. 2.

6. Leininger M (1978) Transcultural Nursing: Concepts, Theories and Practices. New York, John Wiley and Sons.

7. Hanssen I (2002) Facing Differences: Empirical inquiry into ethical challenges in intercultural nursing. $\mathrm{PhD}$ dissertation. Oslo University, Institute of Nursing Science, Osloforlaget.

8. Hawthorne L (2001) The globalization of nursing workforce: barriers confronting overseas qualified nurses in Australia. Nursing Inquiry 8: 213-229.

9. Lovenstein A, Glanville C (1995) Cultural Diversity and Conflict in the Health Care Workplace. Nursing Economics 13: 203-209.

10. Alexis, Chambers (2003) Exploring Alexi's Model: Part two valuing resources: in the second article, Nursing management.

11. Dreyfus H, Dreyfus S (1991) Intuitiv Expertise: den bristede drøm om tælende maskiner, Kobenhavn; Munksgaard. 224 sider.

12. Benner MP, Sutphen M, Moreover L, Day L (2010) Foreword by Lee. S Shulman. Educating nurses: A call for radical Transformation.1st ed. San Francisco, California: Jossey-Bass.

13. Baldonado A, Holm K, Nemivant EB (1997) Cultural/Ethnicity Issues in the classroom. Loyola University of Chicago, Chicago Illinois, Hoitotiede 9: 231-6.

14. Zhou Y, Windsor C, Theobald K, Coyer F (2011) The concept of difference and the experience of China-educated nurses working in Australia: A symbolic interactionist exploration Int J Nurs.

15. Baumann A, Blyethe J, McIntosh K (2006) Internationally Educated Nurses in Ontario: Maximizing the brain Gain. McMaster University, Hamilton, ON.

16. Bleney D, Goodwill (1995) Valuing Diversity: Facilitating Cross-cultural Communication and Conflict Resolution. Working Together (Aust.) Pty Ltd.

17. Konmo R (2006). Support for overseas qualified nurses in adjusting to Australian Nursing Practice: a systematic review. Int J Evidence-Based Healthcare 4: 83-100. 
18. Kawi J, Xu Y (2009) Facilatators and barriers to adjusment of international nurses: an integrative review. International Nursing Review, International Council of Nurses.

19. Campinha BJ (2002).

20. Meleis AI (1996) Culturally Competent Scholarship: Substance and Rigor. Adv. Nur.Science 19: 1-16.

21. Schei B (1998) Aksjonsforskning. I: Lorentsen, M. (red): Spøsrmålet bestemmer metoden- forskningsmetoder I sykepleie og andre helsefag. Oslo: Universitetsforlaget.

22. Smith LT, Lincoln YS, Densin NK (eds) (2008) Handbook of Critical and Indigenous Methodologies.

23. McNiff J, Whitehead J (2002) Action Research: principles and practice (2nd Ed.). 